Scaling Equation for yield strength of nanoporous open-cell foams

A.M. Hodge, J. Biener, J.R. Hayes, P.M. Bythrow, C.A.Volkert, A.V. Hamza

June 5, 2006

Acta Materialia 
This document was prepared as an account of work sponsored by an agency of the United States Government. Neither the United States Government nor the University of California nor any of their employees, makes any warranty, express or implied, or assumes any legal liability or responsibility for the accuracy, completeness, or usefulness of any information, apparatus, product, or process disclosed, or represents that its use would not infringe privately owned rights. Reference herein to any specific commercial product, process, or service by trade name, trademark, manufacturer, or otherwise, does not necessarily constitute or imply its endorsement, recommendation, or favoring by the United States Government or the University of California. The views and opinions of authors expressed herein do not necessarily state or reflect those of the United States Government or the University of California, and shall not be used for advertising or product endorsement purposes. 


\title{
Scaling Equation for yield strength of nanoporous open-cell foams
}

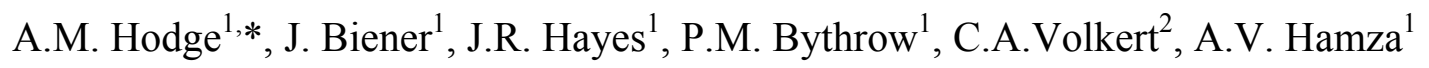 \\ Nanoscale Synthesis and Characterization Laboratory, Lawrence Livermore National \\ Laboratory \\ P.O. Box 808, L-352, Livermore, California 94550 USA \\ ${ }^{2}$ Forschungszentrum, Karlsruhe, Germany
}

\begin{abstract}
A comprehensive study on the relationship between yield strength, relative density and ligament sizes is presented for nanoporous Au foams. Depth-sensing nanoindentation tests were performed on nanoporous foams ranging from 20 to $42 \%$ relative density with ligament sizes ranging from 10 to $900 \mathrm{~nm}$. The Gibson and Ashby yield strength equation for open-cell macro-cellular foams is modified in order to incorporate ligament size effects. This study demonstrates that at the nanoscale, foam strength is governed by ligament size, in addition to relative density. Furthermore, we present the ligament length scale as a new parameter to tailor foam properties and achieve high strength at low densities.
\end{abstract}

Keywords: nanoporous, foams, scaling equations, dealloying 


\section{Introduction}

The effects of scaling (macro to nano) on the mechanical behavior of materials has been a subject of intensive studies and discussion [1-6]. As new materials such as nanoporous foams are developed, scaling relationships are constantly redefined. In bulk materials it has been shown that at the nanoscale $(<100 \mathrm{~nm})$, grain size and sample size affect the overall mechanical behavior and give rise to very distinct mechanical properties, such as higher strength $[4,6,7]$. Therefore, it is expected that nanoporous materials having pores sizes $<100 \mathrm{~nm}$ would also behave differently from macro-cellular foams.

Gibson and Ashby [8] have developed scaling equations for open-cell and closed cell foam by using mathematical relationships between the foam relative density (ratio of the density of the foam to the density of the bulk material) and the bulk material mechanical properties. Their equations are derived using the mechanics of deformation on an "idealized" cell geometry in conjunction with mechanical test data from macro pore size foams. These scaling equations have been shown to describe quite well the overall foam behavior for many different types of macro-cellular (micron and millimeter size pores) foams [9-13].

In the case of nanoporous foams, there has been no previous research providing a systematic study of the scaling equations and how they correspond at the nanoscale. Dealloyed gold foams provide an excellent system for such a study, since they can be synthesized with a wide range of densities as well as a wide range of pore sizes (nanometers to microns ) without changing the overall morphology [14]. In the case of nanoporous gold foam there are at least three available methods to change the 
ligament size: a) by the dealloying method (free corrosion vs. potentiostatically driven) b) by the variation of total dealloying time [15], and c) by a post-dealloying furnace annealing [16].

There have been a number of studies on the mechanical behavior of nanoporous materials and values have been reported for yield strength and elastic modulus. For example, Li and Sieradzki [16] reported a ductile-brittle transition in porous Au, which seemed to be controlled by the microstructural length scale of the material. Biener et al. reported on the high yield strength of nanoporous Au foams [17] and their fracture behavior as a function of the length scale [18]. More recently, Volkert et. al have performed micro-compression tests on dealloyed nanoporous Au foam columns $(36 \%$ relative density, 5-10 a.t.\% residual silver) and have suggested that the Gibson and Ashby equation should be modified by substituting the yield strength of fully dense Au (2$200 \mathrm{MPa}$ ) to account for the increase in measured yield stress [19]. Additionally, Biener et. al presented a similar conclusion about the need to account for the scaling effects which relate strength and ligament size [20].

In this paper, we present a comprehensive study of open-cell nanoporous $\mathrm{Au}$ foams with relative densities ranging from 20 to $42 \%$ and compare the experimental values to the Gibson and Ashby scaling equation for yield strength. We address issues such as ligament size, pore size and relative density in order to present a link between the mechanical behavior in nanoporous foams to macro pore size foams. An empirical formula is presented which relates relative density and ligament size to the foam yield strength.

\section{Experimental}




\subsection{Foam Processing}

The nanoporous $\mathrm{Au}$ samples used in the present study were made by electrochemically-driven dealloying or free corrosion of $\mathrm{Au} / \mathrm{Ag}$ alloys. Polycrystalline $\mathrm{Au}_{\mathrm{x}} \mathrm{Ag}_{100-\mathrm{x}}($ where $\mathrm{x}=42$ to 20 at.\%) alloy ingots were prepared from an $\mathrm{Au}(99.999 \%)$ and $\mathrm{Ag}(99.999 \%)$ melt at $1100^{\circ} \mathrm{C}$ and homogenized for 100 hours at $875^{\circ} \mathrm{C}$ under argon. Approximately $5.0 \mathrm{~mm}$ diameter, $300 \mu \mathrm{m}$ thick disks were cut from the alloy ingots, polished on one side, and then heat-treated for 8 hours at $800{ }^{\circ} \mathrm{C}$ to relieve stress. The alloy composition was confirmed by a fire assay technique.

Nanoporous Au samples prepared by selective electrolytic dissolution were dealloyed in 1 mole $\mathrm{HNO}_{3}$ and 0.01 mole $\mathrm{AgNO}_{3}$ solution. A three-electrode electrochemical cell controlled by a potentiostat (Gamry PCI4/300) was used for these experiments. Dealloying was performed at room temperature, using a platinum wire counter electrode and a silver wire pseudo reference electrode. The alloy samples were held at an applied electrochemical potential between $600-900 \mathrm{mV}$ for a period of 2-3 days until the dissolution current measurement was negligible. The nanoporous samples prepared by free corrosion were submerged in a $67-70 \% \mathrm{HNO}_{3}$ solution for $2-3$ days until no further weight loss was detected.

In order to produce a sample with multiple pore/ligament sizes, a $30 \%$ relative density sample was divided into 5 slices, and each slice was subsequently subjected to a heat treatment in air for 2 hours at $200,300,400$, and $600^{\circ} \mathrm{C}$.

\subsection{Foams Characterization and testing}

Scanning electron microscopy (SEM), transmission electron microscopy (TEM), and X-ray diffraction (XRD) were employed for microstructural characterization. TEM 
samples were prepared by microtome slicing as well as focused ion beam (FIB) milling. Energy dispersive X-ray (EDX) spectra were collected for all nanoporous Au samples, thus confirming that the remaining $\mathrm{Ag}$ concentration was less than 1.0 at. $\%$ after dealloying. Sample density was then estimated using the starting alloy composition, and the remaining $\mathrm{Ag}$ content was estimated by assuming no volume shrinkage. Sample thickness and diameter were measured before and after dealloying; dimensional changes were determined to be negligible. Additionally, the calculated sample volume and measured mass (before and after dealloying) were utilized to verify sample density.

The mechanical properties of nanoporous $\mathrm{Au}$ were tested by depth-sensing nanoindentation using a Triboindenter (Hysitron) with a Berkovich tip (radius of $\sim 200$ nm). Indentations were performed on the planar, "polished surface" (polished before dealloying) of the sample disks as well as on cross-sections produced by fracturing the sample. All foam nanoindentation experiments were performed using a constant loading rate of $500 \mu \mathrm{N} / \mathrm{s}$ with loads ranging from 200 to $4000 \mu \mathrm{N}$. A minimum of 125 indents, performed in groups of 25 were collected for each sample.

\section{Results}

3.1 Dealloying results

As mentioned in the introduction, use of different dealloying techniques, allow us to alter the ligament scales of the foams. Since Au does not oxidize in air even at elevated temperatures, the pore/ligament dimensions can easily be fine tuned between $\sim 100 \mathrm{~nm}$ to $1 \mu \mathrm{m}$ by a simple furnace anneal. The underlying principle behind all these methods is Ostwald ripening, by the formation of more thermodynamically stable larger structures by diffusion. However, in order to make a complete assessment of the 
mechanical properties, a wide range of densities is also necessary. Currently, Au foam can be produced by dealloying, in a range between 20 to $40 \%$ relative density. Relative densities below $20 \%$ and above $60 \%$ are limited by percolation limits when using $\mathrm{Ag} / \mathrm{Au}$ alloy [21, 22]. Furthermore, foams above $40 \%$ relative density are expected to have significantly different behavior from lower density foams [8] and therefore will not be discussed in this paper.

Table 1 presents a summary of the results from samples ranging from 20 to $40 \%$ relative density given different processing conditions and their corresponding ligament size. The relative density is defined as $\rho^{*} / \rho_{\mathrm{s}}$; where $\rho^{*}$ is the foam density and $\rho_{\mathrm{s}}$ is the bulk material density [8]. Figure 1 shows a 30\% relative density Au sample which was divided into five samples $C$ thru G. Sample $C$ was not annealed; sample F was annealed for two hours at $400^{\circ} \mathrm{C}$ and sample $\mathrm{G}$ was annealed for two hours at $600^{\circ} \mathrm{C}$. Samples F and $\mathrm{G}$ exhibit pore and ligament size growth up to 15 times larger than the original dealloyed structure. SEM micrographs, similar to those presented in Figure 1, were used to measure hundreds of pores and ligaments in each sample. Figure 2 presents the ligament size distribution for $25 \%$ and $30 \%$ relative density foams. It should be noted that for all un-annealed samples, we found the pore-to-ligament size ratio to be $\sim 1$. Further details of pore changes as a function of temperature can be found elsewhere [14, $16]$. 
To be submitted to Acta Materialia - not for circulation

\subsection{Nanoindentation}

In the case of plastic indentation, it has been demonstrated that for foams with relative densities less than $30 \%$, the hardness $(\mathrm{H})$ is approximately equal to the yield strength $\left(\sigma_{\mathrm{y}}\right)$ rather than $\mathrm{H} \sim 3 \sigma_{\mathrm{y}}$ which characterizes a fully dense material [8]. Therefore, throughout this paper, we will use this assumption to assess the yield strength from the hardness data. A more detailed discussion of the validity of this assumption can be found in section 4.2 .

Figure 3 shows the loading/unloading curves for the 30\% relative density sample as dealloyed and heat treated at 300 and $400^{\circ} \mathrm{C}$ with ligament sizes of 60,160 and $480 \mathrm{~nm}$ respectively. By analyzing this data using the Oliver Parr method one can calculate the hardness and modulus values [23]. Note that the curves for a given sample overlap independent of indentation depth, thus showing homogeneity through the sample thickness. Figure 4 represents data for $25 \%$ and $30 \%$ relative density samples plotted as a function of contact pressure vs. indentation depth. Values from figure 4 show that the hardness decreases with increasing indentation depth, and approaches a "steady state" value for indentation depths greater than $500 \mathrm{~nm}$. Furthermore, hardness values were validated by using the peak indentation load $P_{\max }$ to the projected indentation area $A_{p}$ of the residual indent impression on SEM micrographs [17].

A summary of all tests performed and the Gibson and Ashby prediction for yield strength (eqn. 1) is shown in Figure 5. Since material values for bulk gold yield stress are quite scattered $(10-200 \mathrm{MPa})[24,25]$ we use the highest value as the input for $\sigma_{\mathrm{s}}$ in equation 1. Figure 5 is a plot of the normalized yield stress vs. relative density including experimental data and noting data according to the ligament size. It should be 
emphasized that as the ligament size approaches $1.0 \mu \mathrm{m}$ the data begins to approach the Gibson and Ashby scaling prediction,

$$
\sigma^{*}=C_{2} \sigma_{S}\left(\frac{\rho^{*}}{\rho_{s}}\right)^{3 / 2}
$$

where $*$ denotes foam properties and $s$ denotes solid properties. The coefficient $C_{2}$ is 0.3 as given by Gibson and Ashby.

\subsection{Discussion}

\subsection{Nanoindentation Technique Validation}

The use of indentation as a tool to measure foam hardness on macro size foams is well documented in the literature [26-30]. Strength values from compression and indentation tests have been shown to give equivalent values for low density foams when the indenter is large relative to the cell size ( $>10$ times the cell size) [26]. Most recently Chen et. al. presented a study comparing nanoindentation, bulge test measurements and Finite Element Analysis (FEA) as techniques to measure the mechanical properties of thin polymers films (23\% porosity) and found that nanoindentation presented similar values to other tests and simulations as long as sample densification was accounted for [31]. In the current study, we use nanoindentation to quantify the nano foam mechanical behavior. First, we address indentation size effects issues in order to present representative values for each foam. All samples were indented to depths ranging from $100 \mathrm{~nm}$ to $2 \mu \mathrm{m}$; note that even the deepest indents correspond to less than one percent of the total sample thickness $(250-300 \mu \mathrm{m})$. In the case of densification effects, it has been shown that, during indentation, the area underneath the indenter is compressed and 
densified, while area outside the indentation diameter remains undeformed [26, 28, 32]. This result is consistent with our previous observations on nanoporous foams [17]. As shown in Figure 4, we see an exponential decay in hardness as a function of indentation depth, which appears to plateau after indentation depths larger than $500 \mathrm{~nm}$. All values presented in Figure 5 have been taken from this "plateau" area. The issue of indentation size effects was previously addressed by Andrews et al., who performed a detailed study of specimen size effects compared to cell size using indentation on $\mathrm{Al}$ open cell (20 pores per inch) foams [26]. Their results show an exponential decay in hardness as a function of the normalized indenter size/cell size [26]. In the current study, a similar effect is observed and appears more pronounced for the samples with smaller ligament size.

Another issue regarding indentation is the assumption that $\mathrm{H} \sim \sigma_{\mathrm{y}}$, which characterizes a fully compressible material. During indentation, low density foam deformation underneath the indenter has been shown to be mostly plastic, and thus mostly compressible; areas outside the indentation area have been shown to remain undeformed, which is consistent with a fully compressible material [17, 26, 28, 32, 33]. Although low density foams have been shown to have non-zero Poisson's ratio [11, 19], in the case of indentation we are specifically referring to the "lateral expansion coefficient" or "plastic Poisson's ratio $\left(v_{p}\right)$ " which typically approaches zero for low density foams $[34,35]$. For example, the Poisson's ratio of low density open-cell aluminum (Duocel) foams have been shown to be $\sim 0.25$ [11], while the plastic Poisson's ratio is reported to be $\sim 0.052$ [34]. Therefore, using the relationship $\mathrm{H} \sim \sigma_{\mathrm{y}}$ appears to be a reasonable assumption for low density nanoporous foams tested by nanoindentation. 


\subsection{Comparison to Gibson and Ashby Equations}

Due to the possible applications of nanoporous foams, such as for sensors and actuators $[36,37]$ it is important to study the mechanical behavior of nanoporous foams and compare that behavior to their macro-cellular counterparts. As shown in Figure 5 the experimental data for the normalized yield strength vs. relative density of nanoporous foams deviates from the Gibson and Ashby predictions. It is has been stated before that this type of nanoporous material is up to 15 times stronger than predicted and approaches the theoretical strength of $\mathrm{Au}[17]$.

Previous studies on macro-cellular foams have investigated the effects of cell geometry and relative density of foams and concluded that given a similar porosity the cell size had a minimal effect in the mechanical behavior [38, 39]. However, this is not the case for the nanoporous foams. For example the $30 \%$, relative density samples (A thru $\mathrm{G}$ in Table 1) have the same relative density and ligament sizes ranging from 40 to $900 \mathrm{~nm}$; in Figure 5 and Table 1 a strong relationship is observed as a function of ligament size i.e increasing the ligament size decreases the hardness or yield strength. The same effect can be seen for the $25 \%$ relative density sample for three distinct ligament sizes (created by changing dealloying conditions): 10, 30 and $50 \mathrm{~nm}$. It should be noted that as the ligament size approaches 1.0 micron (sample $30 \mathrm{G}$ ), the data begins to approach the Gibson and Ashby prediction. Note that the hardness/yield strength standard deviation for all samples in Figure 5 is less than $5 \%$, except for the $900 \mathrm{~nm}$ ligament size sample $(30 \mathrm{G})$ which was tested by Vickers indentation (to avoid indentation size effects). 


\subsection{Yield strength scaling equation}

As covered in section 4.2, nanoporous foams do not follow directly the Gibson and Ashby relationship between yield strength and relative density (Eqn. 1). In order to understand the length scale effect revealed by Figure 5, we use Equation 1 to calculate the yield strength of the ligaments in nanoporous Au. Figure 6 shows a Hall-Petch type plot of the calculated ligament yield strength $\left(\sigma_{\mathrm{yc}}\right)$ versus the inverse square root of the ligament size (L). Also included in Figure 6 is the yield strength obtained from a microcompression test on sample $30 \mathrm{~B}$ (at about 5\% compression) [20]. The calculated ligament yield strength $\left(\sigma_{\mathrm{yc}}\right)$ follows the relationship to $\mathrm{L}^{-1 / 2}$, and can be expressed as

$$
\sigma_{y c}=\left(\sigma_{0}+k_{A u} \cdot L^{-1 / 2}\right)
$$

where $\sigma_{0}$ is related the bulk material yield strength $\left(\sigma_{\mathrm{s}}\right)$, and $\mathrm{k}_{\mathrm{Au}}\left(\mathrm{MPa} \cdot \mathrm{nm}^{1 / 2}\right)$ is a material constant which describes the yield strength size-dependence in the regime of $10 \mathrm{~nm}$ to 1 $\mu \mathrm{m}$.

Fitting the data shown in Figure 6 using Equation 2 (solid line) reveals the following Hall-Petch parameters: $\sigma_{\mathrm{yc}}(\mathrm{MPa})=200+982{ }^{*} \mathrm{~L}^{-1 / 2}(\mathrm{~nm})$. This is consistent with previous research on nanocrystalline gold films ( $\mathrm{k}$ value of $9200 \mathrm{MPa} \cdot \mathrm{nm}^{1 / 2}$ for 26 $60 \mathrm{~nm}$ grains) [40], and sample-size effect studies of Au (k values ranging 1900 to 7900 MPa.nm ${ }^{1 / 2}$ for $10 \mathrm{~nm}-1 \mu \mathrm{m}$ length scales). This result indicates that presence of grain boundaries (nanocrystalline materials) and surfaces (sample volume effect) gives rise to very similar strengthening behavior. Combining Equations 1 and 2 leads to a modified foam scaling equation. 


$$
\sigma^{*}=C_{S}\left[\sigma_{0}+k \cdot L^{-1 / 2}\right] \cdot\left(\frac{\rho}{\rho}\right)^{3 / 2}
$$

where $\mathrm{C}_{\mathrm{s}}$ is a fitting coefficient, $\sigma_{0}$ is the bulk material yield strength $\left(\sigma_{\mathrm{s}}\right), \mathrm{k}$ is the Hall Petch type coefficient for the theoretical yield strength of Au in the regime $(10 \mathrm{~nm}$ to 1 $\mu \mathrm{m})$, and $\mathrm{L}$ is the ligament size. For macroporous foams $(\mathrm{L}>>500 \mathrm{~nm}), \mathrm{k} \cdot \mathrm{L}^{-1 / 2}$ becomes negligible and Equation 3 yields Equation 1.

\subsection{Foam ligaments as a high strength material}

Factors in addition to the ligament size that could give rise to the high strength of the nanoporous materials include: grain size, testing method and densification. The agreement with the micro-compression tests indicates that the effect is not an indentation size effect. The fact that the increase of strength with decreasing ligament size is observed for a fixed initial foam density reveals that the defect cannot be due to densification effects. In a previous publication we have presented that our particular foam processing method produce ligaments that have a nanocrystalline grain structure [41]. The grain structure or lack thereof during dealloying is still a subject of debate and is beyond the scope of this paper [14]. However, even if we assume the ligaments are nanocrystalline, it still does not account for the high strength found experimentally since the yield strength of a nanocrystalline Au sample $[41,42]$ is only 4 times higher than that of coarse grained $\mathrm{Au}$.

The increase in hardness in the nanoporous gold foam can be attributed to many factors. However, one can apply a new approach to the discussion about the increase in strength by visualizing the foam as a three-dimensional network of high strength 
ligaments as proposed by Biener et al. [20]. Recent developments from tests performed on ultra-fine and micron size $(180 \mathrm{~nm}-8 \mu \mathrm{m})$ single crystal gold pillars prepared by FIB, have demonstrated a strong pillar size dependence on the material strength. As the pillar size decreases the yield strength of the pillar approaches the theoretical yield strength of $\mathrm{Au}[2,4]$. Due to FIB size fabrication limits, the tested columns are larger than a typical foam ligament size, thus preventing a complete size comparison between both methods. However, in the overlapping length scale range ( $200 \mathrm{~nm}-1$ micron), we observe good agreement between the calculated ligament yield strength and the single-crystal column micro-compression tests [2].

The effect of the ligament size on ligament strength is evident; however, the mechanisms are not well understood. There are two general categories of explanations for such a size effect. Either (1) the dislocations are depleted from the small sample volumes and deformation is limited by dislocation source activation, as is typically observed in fine-grained materials, or (2) the dislocations interact and pile up and high dislocation densities are required to explain the high stresses. Whether the ligament surface allows or hinders dislocation egression will play a decisive role in the dominating deformation mechanism. Reliable TEM observations can generally distinguish between the two scenarios, however a detailed understanding of the strengthening effect, particularly in the complex foam geometry, will require computer simulation studies. In order to unify data from nanoporous foam and single pillar compression tests, we will present MD simulations and quasi-continuum simulations in a future publication. 


\section{Conclusions}

We have presented a comprehensive study of nanoporous $\mathrm{Au}$ foams with relative densities ranging from 20 to $42 \%$ and ligament sizes ranging from 10 to $900 \mathrm{~nm}$. We observe that at the nanoscale, the strength is not only controlled by the relative foam density (as in the case of macro-cellular foams), but also by the ligament length scale. In order to account for this length scale effect, we modify the Gibson and Ashby scaling equation by incorporating a Hall-Petch type relation $\left(\sigma_{0}+\mathrm{k}_{\mathrm{Au}} \cdot \mathrm{L}^{-1 / 2}\right)$. In general, our results indicate that the presence of grain boundaries (nanocrystalline materials) and surfaces (sample volume effect) give rise to very similar strengthening behavior.

Testing effects were also evaluated in order to substantiate the significance of the experimental results. Nanoindentation is shown to be a valid testing technique for low density nanoporous materials as long as the proper parameter space is used.. Overall, nanoporous $\mathrm{Au}$ foams are presented as a new type of high strength, low density materials with the possibility for a wide range of applications.

\section{Acknowledgements}

This work was performed under the auspices of the U.S. Department of Energy by University of California, Lawrence Livermore National Laboratory under Contract W7405-Eng-48. The authors thank J. Ferreira for SEM, J.A. Caro for sample characterization; and Drs. L.M. Hsiung, L. Zepeda, F. Abrahimi, Y.M. Wang at LLNL, and Professor L. Gibson at MIT for helpful discussions. 
Table 1. Sample processing method and ligament size

\begin{tabular}{|l|l|l|}
\hline Relative density (\%) & Processing method* & \multicolumn{1}{c|}{$\begin{array}{c}\text { Average Ligament size } \\
(\mathrm{nm})\end{array}$} \\
\hline $42 \mathrm{~A}$ & EC & 100 \\
\hline $42 \mathrm{~B}$ & EC & 40 \\
\hline $35 \mathrm{~A}$ & FC & 50 \\
\hline $30 \mathrm{~A}$ & FC & 50 \\
\hline $30 \mathrm{~B}$ & FC & 40 \\
\hline $30 \mathrm{C}$ & FC & 60 \\
\hline $30 \mathrm{D}$ & FC then HT $200^{\circ} \mathrm{C}, 2 \mathrm{hrs}$. & 60 \\
\hline $30 \mathrm{E}$ & FC then HT $300^{\circ} \mathrm{C}$ & 160 \\
\hline $30 \mathrm{~F}$ & FC then HT $400^{\circ} \mathrm{C}$ & 480 \\
\hline $30 \mathrm{G}$ & FC then HT $600^{\circ} \mathrm{C}$ & 900 \\
\hline $25 \mathrm{~A}$ & FC & 50 \\
\hline $25 \mathrm{~B}$ & FC & 30 \\
\hline $25 \mathrm{C}$ & EC & 5 \\
\hline $25 \mathrm{D}$ & FC then HT $400^{\circ} \mathrm{C}$ & 200 \\
\hline $20 \mathrm{~A}$ & EC & 20 \\
\hline
\end{tabular}

*FC denotes by free corrosion, EC denote potentiostically driven, HT denotes heat

treatment

\section{References}

[1] Uchic MD, et al., Science 2004; 305: 986.

[2] Volkert C.A. and Lilleodden E., Philos. Mag. A 2006; in press.

[3] Nix W.D. and Gao H., J. Mech. Phys. Solids 1998; 46: 411.

[4] Greer J.R., Oliver W.C., and Nix W.D., Acta Mater. 2005; 53: 1821.

[5] Manika I. and Maniks J., Acta Mater. 2006; in press.

[6] Suryanarayana C., Inter. Mater. Rev. 1995; 40: 41.

[7] Kumar K.S., Van Swygenhoven H., and Suresh S., Acta Mater. 2003; 51: 5743.

[8] Gibson L.J. and Ashby M.F., Cellular Solids: Structures and Properties. Second ed. 1997: Cambridge University Press.

[9] Andrews E.W., Gibson L.J., and Ashby M.F., Acta Mater. 1999; 47: 2853.

[10] Andrews E.W., Huang J.-S., and Gibson L.J., Acta Mater. 1999; 47: 2927.

[11] Andrews E., Sanders W., and Gibson L.J., Mater. Sci. Eng. 1999; 270A: 113.

[12] Zhu H.X. and Mills N.J., J. Mech. Phys. Solids 1999; 47: 1437.

[13] Zhu H.X., Hobdell J.R., and Windle A.H., Acta Mater. 2000; 48 : 4893.

[14] Hodge A.M., et al., Adv. Eng. Mater. 2006; in press.

[15] Ding Y., Kim Y.-J., and Erlebacher J., Adv. Mater. 2004; 16: 1897.

[16] Li R. and Sieradzki K., Phys. Rev. Lett. 1992; 68: 1168.

[17] Biener J., et al., J. Appl. Phys. 2005; 97: 024301.

[18] Biener J., Hodge A.M., and Hamza A.V., Appl. Phys. Lett. 2005; 87: 121908. 
[19] Volkert C.A., et al., Appl. Phys. Lett. 2006; in press.

[20] Biener J., et al., Nature Mater. 2006; submitted.

[21] Newman R.C. and Corcoran S.G., MRS Bull. 1999; $24: 24$.

[22] Sieradzki K., et al., J. Electrochem. Soc. 2002; 149: B370.

[23] Oliver W.C. and Pharr G.M., J. Mater. Res. 1992; 7: 1564.

[24] Savitskii E.M., ed. Handbook of Precious Metals. 1989, Hemisphere Publishing Corporation: New York.

[25] Davies J.R., ed. Metals Handbook. 2nd ed. 1998, ASM international: Materials Park. 626.

[26] Andrews E.W., et al., Int. J. Mech. Sci. 2001; 43: 701.

[27] Liu Z., Chuah C.S.L., and Scalon M.G., Acta Mater. 2003; 51: 365.

[28] Wilsea M., Johnson K.L., and Ashby M.F., Int. J. Mech. Sci. 1975; 17: 457.

[29] Toivola Y., Stein A., and Cook R.F., J. Mater. Res. 2004; 19: 260.

[30] Ramamurty U. and Kumaran M.C., Acta Mater. 2004; 52: 181.

[31] Chen X., Xiang Y., and Vlassak J.J., J. Mater. Res. 2006; 21: 715.

[32] Kumar P.S., Ramachandra S., and Ramamurty U., Mater. Sci. Eng. 2003; 347A: 330.

[33] Brydon A.D., et al., J. Mech. Phys. Solids 2005; 53: 2638.

[34] Gioux G., McCormack T.M., and Gibson L.G., Int. J. Mech. Sci. 2000; 42: 1097.

[35] Miller R.E., Int. J. Mech. Sci. 2000; 42: 729.

[36] Erlebacher J., et al., Nature 2001; 410: 450.

[37] Weissmueller J., et al., Science 2003; 300: 312.

[38] Yamada Y., et al., Materials Transactions, JIM 2000; 41: 1136.

[39] Nieh T.G., Higashi K., and Wadsworth J., Mater. Sci. Eng. 2000; 283A: 105.

[40] Sakai Y., Tanimoto H., and Mizubayashi H., Acta Mater. 1999; 47: 211.

[41] Hodge A.M., et al., J. Mater. Res. 2005; 20: 554.

[42] Tanimoto H., et al., Mater. Sci. Eng. 1996; 217/218A: 108. 


\section{Figure Captions}

Figure 1. SEM micrographs of a $30 \%$ relative density foam a) as prepared by free corrosion (sample C) and then heat treated in air at b) $400^{\circ} \mathrm{C}$ (sample F) and c) $600^{\circ} \mathrm{C}$ (sample G).

Figure 2. Distribution of ligament size for two different relative densities a) $25 \%$, b) $30 \%$.

Figure 3. Nanoindentation loading/unloading curves for $30 \%$ relative density sample as a function of ligament size. Sample a) as prepared by free corrosion and sample the heat treated in air at b) $300^{\circ} \mathrm{C}$ and c) $400^{\circ} \mathrm{C}$ given same load and loading rates $(500 \mu \mathrm{m} / \mathrm{s})$, with ligament sizes of $60,160,480 \mathrm{~nm}$, respectively.

Figure 4. Nanoindentation data for a $30 \%$ relative density sample foams plotted as a function of contact pressure vs. indentation depth given three distinct ligament sizes a) $60 \mathrm{~nm}$, b) $160 \mathrm{~nm}$ and c) $480 \mathrm{~nm}$

Figure 5. Experimental values for foam yield stress for all samples shown in Table 1, normalized by the yield stress for fully dense Au. The solid line presents the Gibson and Ashby prediction for a gold foam.

Figure 6. Relationship of ligament size to ligament yield stress for nanoporous gold foams obtained by nanoindentation and by column micro-compression testing [20]. 
To be submitted to Acta Materialia - not for circulation


Figure 1 
To be submitted to Acta Materialia - not for circulation


Figure 3. 
To be submitted to Acta Materialia - not for circulation

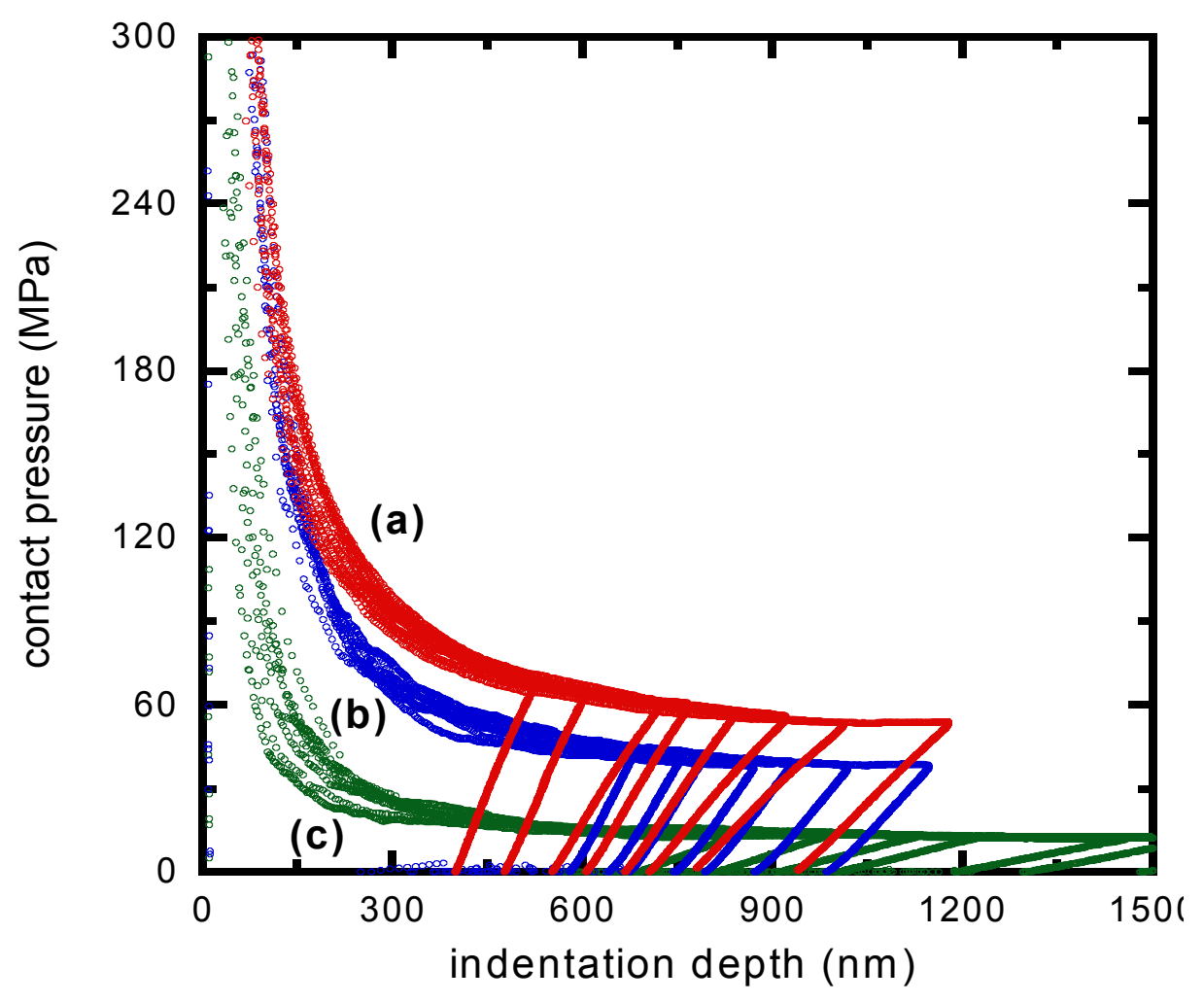

Figure 4. 
To be submitted to Acta Materialia - not for circulation

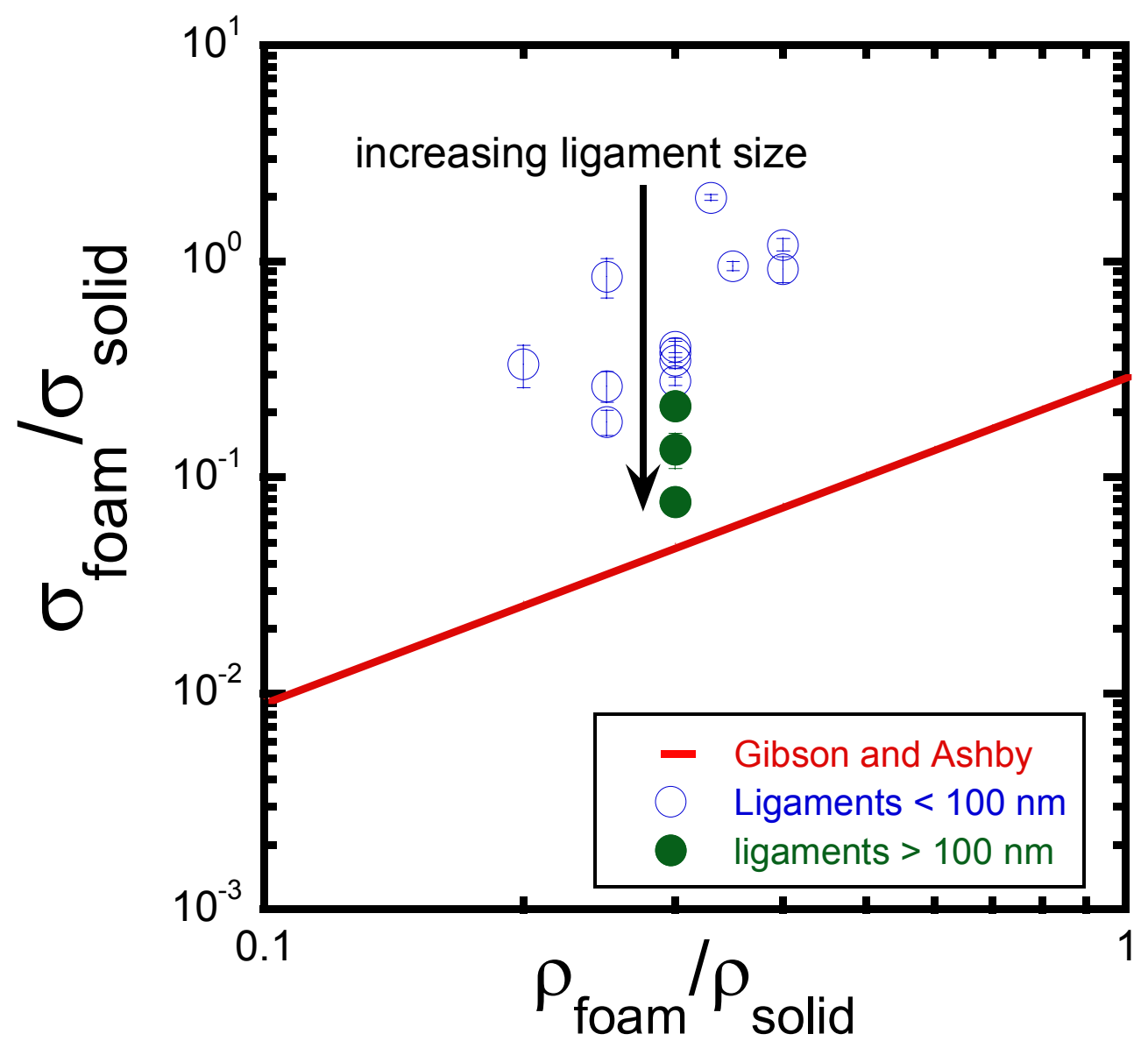

Figure 5 
To be submitted to Acta Materialia - not for circulation

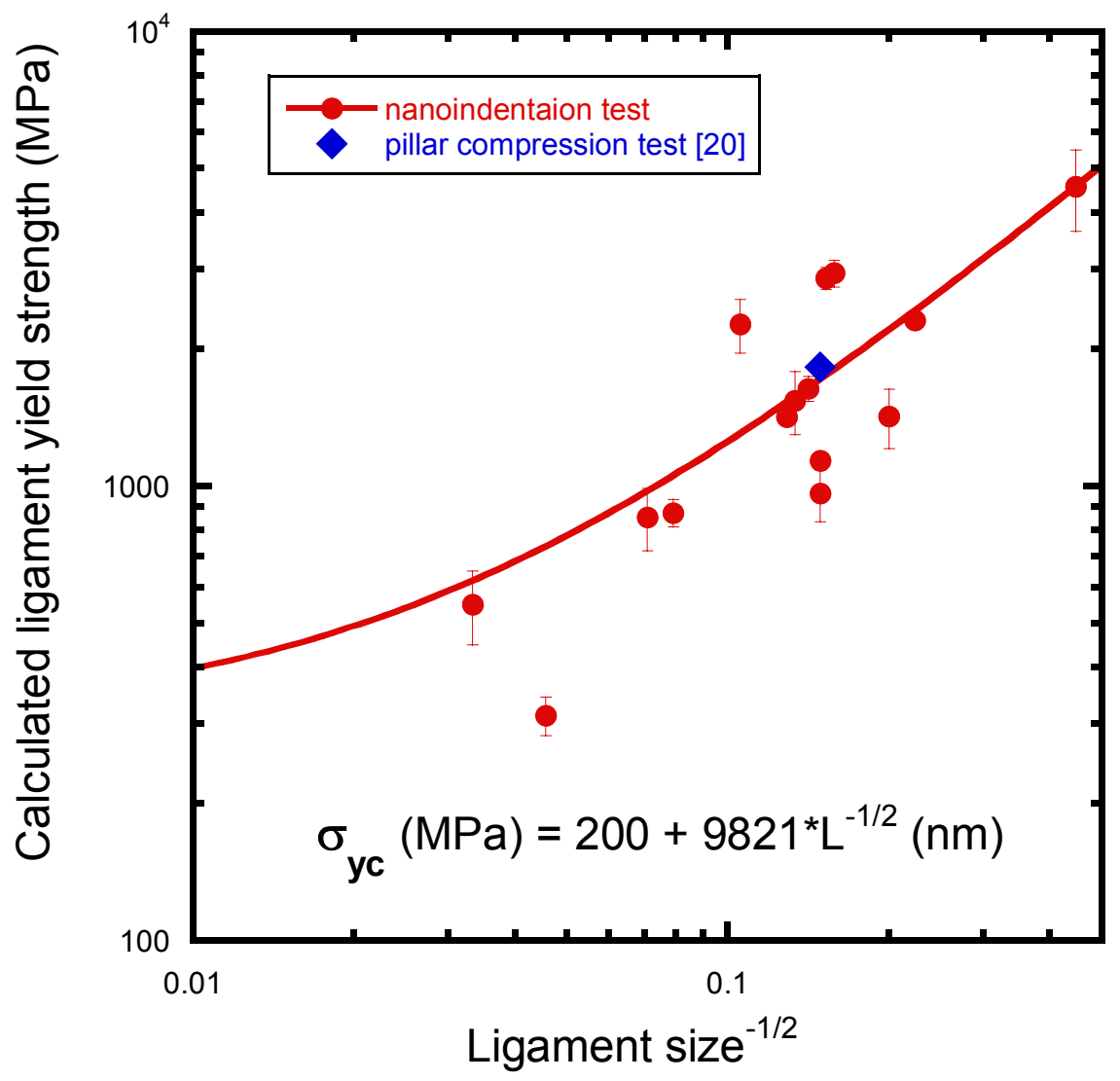

Figure 6 